\title{
Haematological phenotypes in relation to the CI797T $\beta$-adducin polymorphism in a Caucasian population
}

\author{
Ji-Guang WANG*, Cristina BARLASSINA†, Giuseppe BIANCHI \\ Laura ZAGATO $\$$ and Jan A. STAESSEN* \\ *Hypertensie en Cardiovasculaire Revalidatie Eenheid, Departement voor Moleculair en Cardiovasculair Onderzoek, \\ Katholieke Universiteit Leuven, Herestraat 49, 3000 Leuven, Belgium, †Dipartimento di Scienze e Tecnologie Biomediche, \\ Università degli Studi di Milano, Milano, Italy, łCattedra e Scuola di Nefrologia, Università Vita e Salute San Raffaele, \\ Milano, Italy, and §Divisione di Nefrologia Dialisi e Ipertensione, Ospedale San Raffaele, Milano, Italy
}

\section{A}

\begin{abstract}
$\beta$-Adducin plays a role in maintaining the structural integrity of the red blood cell (erythrocyte) membrane. Moreover, $\beta$-adducin-deficient knock-out mice show a phenotype characterized by mild anaemia and compensated haemolysis. We therefore investigated whether, in humans, common haematological phenotypes of red blood cells were associated with a polymorphism in exon 15 of the human $\beta$-adducin gene (CI797T). We studied 802 unrelated individuals and 294 families (459 parents and 609 offspring) randomly selected from a Caucasian population. We employed generalized estimating equations to allow for the non-independence of the observations within families, while controlling for co-variables. In 917 men, with adjustments applied for age, body mass index, serum total cholesterol, smoking and alcohol intake, CC homozygotes had significantly $(P=0.02)$ lower values for red blood cell count $\left(4.93 \times 10^{12} / 1\right.$ compared with $\left.4.86 \times 10^{12} / \mathrm{I}\right)$, haemoglobin level $(9.30$ compared with $9.18 \mathrm{mmol} / \mathrm{l})$ and haematocrit ( $45.0 \%$ compared with $44.4 \%$ ) than $T$ allele carriers. In the 329 men who consumed alcohol, the differences between CC homozygotes and T allele carriers were $0.13 \times 10^{12} / 1(P=$ $0.02)$ for red blood cell count, $0.23 \mathrm{mmol} / \mathrm{I}(P=0.005)$ for haemoglobin and $\mathrm{I} .08 \%(P=0.02)$ for haematocrit. In 953 women, none of these associations was significant $(P \geqslant 0.06)$, regardless of alcohol intake [13.3\% of women $(n=127)$ consmued alcohol]. In conclusion, in men consuming alcohol, the $\beta$-adducin CC genotype was associated with lower red blood cell count, haemoglobin level and haematocrit. We hypothesize that, in CC homozygotes, alcohol consumption may unveil the greater fragility of the red blood cell membrane. This genotype may slightly potentiate the structural and functional haematological disturbances associated with alcohol intake.
\end{abstract}

\section{INTRODUCTION}

The membrane-skeleton protein adducin stimulates the assembly of the spectrin-actin network, which determines the morphology and motility of cells [1]. The activity of adducin in promoting the binding of spectrin with actin filaments is modulated by calmodulin and protein kinases [2]. Adducin is composed of either $\alpha$ and $\beta$ or $\alpha$ and $\gamma$ subunits which, to a large extent, are similar in amino acid sequence and domain organization [1]. The

Key words: adducin, alcohol intake, genetic polymorphism, haemoglobin, red blood cell.

Abbreviations: GEE, generalized estimating equations; $\mathrm{MCH}$, mean corpuscular haemoglobin; MCHC, mean corpuscular haemoglobin concentration; MCV, mean corpuscular volume; RBC, red blood cell; RDW, red cell distribution width.

Correspondence: Dr Jan A. Staessen, Studiecoördinatiecentrum, Laboratorium Hypertensie, Campus Gasthuisberg, Herestraat 49, B-3000 Leuven, Belgium (e-mail jan.staessen@med.kuleuven.ac.be). 
$\alpha$ - and $\gamma$-adducins are expressed in most tissues, whereas $\beta$-adducin is abundant in brain and red blood cells (RBCs; erythrocytes). Using the targeted gene knock-out approach, two studies consistently found that $\beta$-adducindeficient mice showed a phenotype of mild compensated haemolytic anaemia characterized by increased osmotic fragility and spherocytosis [3] or elliptocytosis [4].

The human $\beta$-adducin gene is localized to chromosome 2 p13 and comprises 17 exons [5]. A common singlenucleotide polymorphism $(\mathrm{C} \rightarrow \mathrm{T})$ in the $\beta$-adducin gene has been identified at position 1797 of exon 15 (C1797T, starting from ATG; SNP number rs4984; URL: http:// www.ncbi.nlm.nih.gov/SNP/). This change is silent in terms of the amino acid composition of $\beta$-adducin. However, alternative splicing including exon 15 causes a frame shift and early termination, yielding $\beta$-adducin isoform 4, which is a smaller polypeptide with an alternative C-terminus as compared with the originally described isoform 1 [5]. The C-terminal domain contains the spectrin-actin interaction site, as well as the target sequences for calmodulin and protein kinases [1]. In the present study, we investigated the associations between various haematological phenotypes measured in peripheral blood and the $\beta$-adducin C1797T polymorphism in a Caucasian population sample.

\section{METHODS}

\section{Study population}

The protocol of the Flemish Study on Environment, Genes and Health Outcomes (FLEMENGHO) was approved by the Ethics Committee of the University of Leuven. All subjects gave informed consent. From August 1985 until November 1990, a random sample of the households living in a geographically defined area of Northern Belgium [6] was investigated, with the goal of recruiting equal numbers of participants in each of six subgroups defined by sex and age (20-39, 40-59 and $\geqslant 60$ years). All household members with a minimum age of 20 years were invited to take part, until the quota of their sex/age group had been fulfilled. To study further the role of genetic factors, from June 1996 until December 2000, nuclear families including children who were at least 10 years old were recruited, using the former participants (1985-1990) as index persons.

The study population included 2310 subjects. The participation rate among the subjects contacted was $66.1 \%$. For 37 participants, haematological measurements had not been performed. Blood for DNA extraction could not be obtained from 403 former participants, because they did not consent $(n=161)$, had died $(n=180)$, were terminally ill $(n=28)$ or had moved out of the area $(n=34)$. Thus the present analysis included 1870 subjects.

\section{Measurement of phenotypes and co-variables}

Venous blood samples were collected into EDTAcontaining tubes. Red blood cell (RBC) count, haemoglobin, haematocrit and red cell distribution width (RDW) were measured in whole-blood specimens with a SYSMEX HST 403XE model automated cell counter (Systmex Corporation, Chuku, Kobe, Japan). Mean corpuscular volume (MCV) was calculated as (haematocrit $/ \mathrm{RBC}) \times 10$, mean corpuscular haemoglobin $(\mathrm{MCH})$ as haemoglobin/RBC, and mean corpuscular haemoglobin concentration (MCHC) as haemoglobin/ haematocrit. Serum ferritin was measured by means of an automated latex immunoassay [7].

We used a standardized and validated [8] questionnaire to collect information on medical history, smoking habits, intake of alcohol, use of medications and the menstrual cycle of women. For statistical analysis, we expressed alcohol intake as a dichotomous variable or in g per day.

\section{Determination of genotypes}

Genomic DNA was extracted from peripheral blood. Allelic discrimination of the C1797T $\beta$-adducin polymorphism was carried out using the $5^{\prime}$-nuclease assay [9] on an ABI Prism 7700 apparatus (Perkin Elmer, Foster City, CA, U.S.A.). The forward and reverse primers and the $1797 \mathrm{C}$ and $1797 \mathrm{~T}$ probes employed in the TAQMan ${ }^{\circledR}$ assay were 5'-AGGAACGAGAGCCAGGCTCT-3'， 5'-TTCATCAAAACACACACCTACCAAT-3', 5' -VIC ${ }^{\circledR}$-TTCTTCAGCGTTGCCCTCCACAT-TAMRA ${ }^{\circledR}-3^{\prime}$ and $5^{\prime}-$ FAM $^{\circledR}-{ }^{\circledR}$ TCTTCAGTGTTGCCCTCCACATCTG-TAMRA ${ }^{\circledR}-3^{\prime}$ respectively (where $\mathrm{VIC}^{\circledR}$, TAMRA ${ }^{\circledR}$ and FAM $^{\circledR}$ are dyes used with the TAQMan system). Per $25 \mu$, the PCR fluid contained $50 \mathrm{ng}$ of DNA, $200 \mathrm{nmol}$ of primers, $50 \mathrm{nmol}$ of FAM probe and $100 \mathrm{nmol}$ of VIC probe. The amplification conditions were $50^{\circ} \mathrm{C}$ for $2 \mathrm{~min}$ and $95^{\circ} \mathrm{C}$ for $10 \mathrm{~min}$, followed by 40 cycles at $95^{\circ} \mathrm{C}$ for $15 \mathrm{~s}$ and $62^{\circ} \mathrm{C}$ for $1 \mathrm{~min}$. The genotyping procedure was established after we had confirmed the polymorphism (C1797T, starting from ATG; SNP number rs4984; URL: http:// www.ncbi.nlm.nih.gov/SNP/) by sequencing 17 individuals using the ABI Prism Big Dye Terminator cycle sequencing ready reaction kit (Applied Biosystems). We tested the frequency of the polymorphism in a random population of 250 blood donors from North Italy, and found that the minor allele had a frequency of $15 \%$ in that population. For quality control, $10 \%$ of the DNA samples in our study were genotyped in duplicate in a blinded fashion. Duplicate genotypes were confirmatory in all samples.

\section{Statistical analysis}

For database management and statistical analysis, we used SAS software, version 8.1 (SAS Institute, Cary, NC, 
U.S.A.). Measurements with a skewed distribution were normalized by logarithmic transformation. Comparisons of means and proportions were performed using the standard normal $z$-test and Fisher's exact test respectively. To examine the relationship between the haematological measurements and various environmental and lifestyle factors, we used stepwise multiple linear regression, with the $P$ value for co-variables to enter and stay in the model set at 0.15 . We tested genetic associations using the generalized estimating equations (GEE) approach as implemented in the PROC GENMOD procedure of the SAS package. GEE allows for the nonindependence of the haematological phenotypes within families [10]. We imposed a user-defined intra-familial correlation matrix derived from our own study sample, with adjustments applied for the co-variables and confounders. We selected the identity and logit link functions for continuous and dichotomous independent variables respectively. To test the interaction between the $\beta$ adducin polymorphism and alcohol intake, we defined dummy variables coded 0 or 1 according to the absence or presence of the $\mathrm{T}$ allele or alcohol consumption.

\section{RESULTS}

The study sample consisted of 802 unrelated individuals (including 27 spouse pairs without offspring) and of 297 families containing between one and seven children (459 parents and 609 offspring; median number of offspring per family $=2$ ).

The 917 male and 953 female study participants were of similar age (mean \pm S.D. $43.5 \pm 16.2$ years). Men had a slightly greater body mass index than women $(25.5 \pm 3.9$ compared with $\left.25.1 \pm 5.1 \mathrm{~kg} / \mathrm{m}^{2} ; P=0.05\right)$, and tended to have a lower serum total cholesterol concentration $(5.4 \pm 1.1$ compared with $5.5 \pm 1.2 \mathrm{mmol} / 1 ; P=0.06)$. The proportion of smokers was slightly higher in men than in women $[31.6 \%(n=290)$ compared with $27.5 \%$ $(n=262) ; P=0.05]$. More men than women reported intake of alcohol [35.9\% $(n=329)$ compared with $13.3 \%$ $(n=127), P<0.0001]$. Among male and female drinkers, the median (interquartile range) amount of alcohol consumed per day was $20 \mathrm{~g}(10-31 \mathrm{~g})$ and $10 \mathrm{~g}(6-18 \mathrm{~g})$ respectively. Among the women, 352 (36.9\%) reported natural $(n=305)$ or surgical $(n=47)$ menopause, 185 $(19.4 \%)$ used oral contraceptives and $34(3.6 \%)$ took hormonal replacement therapy.

All haematological measurements were significantly $(P<0.05)$ different between men and women, with the exception of RDW $(P=0.65)$. Further analyses dealt with men and women separately. In both men and women, the various haematological phenotypes were correlated with age, body mass index, serum total cholesterol, smoking and/or alcohol intake (Table 1). The serum ferritin concentration increased with age in women, but not in men. In men, alcohol intake was associated with a lower RDW, but a higher MCV, $\mathrm{MCH}$ and serum ferritin level $(P<0.05)$. In male drinkers, the RBC count was inversely associated with the amount of alcohol consumed per day $(-0.22 \times$ $10^{12} / 1$ per $100 \mathrm{~g}$ of alcohol; $P=0.02$ ), whereas MCV $(+2.5 \mathrm{fl}$ per $100 \mathrm{~g} ; P=0.05)$ and $\mathrm{MCH}(+0.091 \mathrm{fmol} / 1$ per $100 \mathrm{~g} ; P=0.002)$ were correlated positively with alcohol intake. In women drinkers, none of these associations reached statistical significance $(P>0.05)$.

The frequencies of $\beta$-adducin genotypes in 802 unrelated individuals and 459 parents enrolled in the present study did not deviate from Hardy-Weinberg equilibrium (CC 0.79, CT 0.20, TT 0.01; $P=0.66$ ). Similar genotype frequencies were observed in 609 offspring (CC 0.80, CT 0.19 , TT 0.01). In men, both before (Table 2) and after (Table 3) adjustment for age, body mass index, serum total cholesterol, smoking and alcohol intake, GEE analysis demonstrated that $\mathrm{CC}$ homozygotes had significantly $(P \leqslant 0.05$ for all $)$ lower values of RBC count, haemoglobin level and haematocrit than $\beta$-adducin $\mathrm{T}$ allele carriers. In women, with adjustments applied for the same co-variables as in men as well as for use of oral contraceptives, none of the phenotype-genotype associations reached statistical significance (Tables 2 and 3).

In men, both before (Figure 1) and after (Figure 2) adjustments, further GEE analyses showed significant interactions between the $\beta$-adducin polymorphism and alcohol consumption. Indeed, in men who consumed alcohol, CC homozygotes had a significantly lower RBC count, haemoglobin level and haematocrit than $\mathrm{T}$ allele carriers $(P \leqslant 0.02)$. In men who did not consume alcohol, homozygosity for the $\beta$-adducin $C$ allele was associated with a slightly higher RDW $(P \leqslant 0.05)$. Among male drinkers, adjusted GEE analyses demonstratd a doseeffect relationship between the haematological phenotypes and alcohol consumption, which was dependent on the $\beta$-adducin genotype. Indeed, in CC homozygotes, but not in $\mathrm{T}$ allele carriers $(P>0.65)$, the RBC count decreased in proportion to the amount of alcohol consumed per day $\left(-0.31 \times 10^{12} / 1\right.$ per $100 \mathrm{~g}$ of alcohol; $P=$ $0.001)$, with a similar trend for haematocrit $(-1.62 \%$ per $100 \mathrm{~g} ; P=0.07)$. We performed a sensitivity analysis in 273 unrelated male drinkers. By multiple linear regression, with similar adjustments as in the GEE analyses, CC homozygosity $(n=214)$ was associated with lower values for RBC count $\left(-0.15 \times 10^{12} / 1 ; P=\right.$ $0.007)$, haemoglobin level $(-0.23 \mathrm{mmol} / 1 ; P=0.01)$ and haematocrit $(-1.15 \% ; P=0.01)$.

In GEE analyses adjusted for age, body mass index, smoking and alcohol intake, we did not observe any differences in serum ferritin level across the $\beta$-adducin genotypes either in men or in women $(P \geqslant 0.12)$. Furthermore, when assessing men and women combined, the prevalence of biliary stones was $1.41 \%(n=21)$ in CC homozygotes but only $0.52 \%(n=2)$ in T allele carriers. 
Table I Correlates of haematological phenotypes

Significance: ${ }^{*} P \leqslant 0.05 ; \nmid P \leqslant 0.01 ; \ddagger P \leqslant 0.15$ (the $P$ value for co-variables to enter and stay in the model). The unit of age is 10 years rather than I year, i.e. the regression coefficients reflect changes in the haematological parameters per 10 -year increase in age.

\begin{tabular}{|c|c|c|c|c|c|c|c|c|}
\hline & RBC count $\left(10^{12} / I\right)$ & Haemoglobin (mmol/l) & Haematocrit (\%) & MCV (fl) & MCH (fmol) & MCHC (mmol/l) & RDW (\%) & $\log _{10} \backslash[$ Serum ferritin $(\mu \mathrm{g} / /)]$ \\
\hline \multicolumn{9}{|l|}{ Men } \\
\hline$n$ & 917 & 913 & 917 & 917 & 913 & 913 & 524 & 297 \\
\hline$R^{2}$ & 0.10 & 0.10 & 0.09 & 0.10 & 0.12 & 0.01 & 0.02 & 0.04 \\
\hline Intercept & 4.40 & 7.95 & 39.0 & 89.0 & 1.818 & 20.45 & 13.33 & 1.80 \\
\hline \multicolumn{9}{|l|}{ Regression coefficients (mean \pm S.E.M.) } \\
\hline Age $(+10$ years $)$ & $-0.069 \pm 0.008 \uparrow$ & $-0.051 \pm 0.015 \dagger$ & $-0.30 \pm 0.07 \uparrow$ & $0.70 \pm 0.11 \dagger$ & $0.017 \pm 0.003 \uparrow$ & $0.029 \pm 0.022$ & $-0.034 \pm 0.029$ & $0.0003 \pm 0.0184$ \\
\hline Body mass index $\left(\mathrm{kg} / \mathrm{m}^{2}\right)$ & $0.027 \pm 0.003 \uparrow$ & $0.047 \pm 0.006 \dagger$ & $0.23 \pm 0.03 \uparrow$ & $-0.02 \pm 0.05$ & $-0.001 \pm 0.001$ & $-0.002 \pm 0.009$ & $0.023 \pm 0.012 \ddagger$ & $0.011 \pm 0.007 \ddagger$ \\
\hline Serum total cholesterol $(\mathrm{mmol} / \mathrm{l})$ & $0.021 \pm 0.011 \ddagger$ & $0.032 \pm 0.020 \ddagger$ & $0.12 \pm 0.10$ & $-0.17 \pm 0.16$ & $-0.002 \pm 0.003$ & $0.017 \pm 0.030$ & $0.004 \pm 0.042$ & $0.020 \pm 0.024$ \\
\hline Smoking $(0=$ no, $I=$ yes $)$ & $-0.023 \pm 0.025$ & $0.217 \pm 0.044 \dagger$ & $0.91 \pm 0.22 \uparrow$ & $2.32 \pm 0.34 \uparrow$ & $0.053 \pm 0.008 \uparrow$ & $0.061 \pm 0.065$ & $-0.082 \pm 0.087$ & $-0.024 \pm 0.051$ \\
\hline Alcohol intake $(0=$ no, $\mathrm{I}=$ yes $)$ & $-0.019 \pm 0.024$ & $0.071 \pm 0.043 \ddagger$ & $0.23 \pm 0.22$ & $0.85 \pm 0.33 \uparrow$ & $0.023 \pm 0.007 \uparrow$ & $0.058 \pm 0.064$ & $-0.226 \pm 0.086 \uparrow$ & $0.132 \pm 0.052^{*}$ \\
\hline \multicolumn{9}{|l|}{ Women } \\
\hline$n$ & 953 & 947 & 953 & 953 & 947 & 947 & 531 & 315 \\
\hline$R^{2}$ & 0.06 & 0.09 & 0.07 & 0.09 & 0.09 & 0.01 & 0.01 & 0.24 \\
\hline Intercept & 4.08 & 7.41 & 36.6 & 90.0 & 1.827 & 20.28 & 13.86 & 0.72 \\
\hline \multicolumn{9}{|l|}{ Regression coefficients (mean \pm S.E.M.) } \\
\hline Age $(+10$ years $)$ & $-0.052 \pm 0.009 \uparrow$ & $-0.044 \pm 0.015 \uparrow$ & $-0.24 \pm 0.08 \uparrow$ & $0.55 \pm 0.12 \uparrow$ & $0.012 \pm 0.003 \uparrow$ & $0.014 \pm 0.024$ & $0.002 \pm 0.038$ & $0.129 \pm 0.020 \uparrow$ \\
\hline Body mass index $\left(\mathrm{kg} / \mathrm{m}^{2}\right)$ & $0.013 \pm 0.002 \uparrow$ & $0.016 \pm 0.004 \uparrow$ & $0.10 \pm 0.02 \uparrow$ & $-0.04 \pm 0.03$ & $-0.002 \pm 0.001^{*}$ & $-0.012 \pm 0.006 \ddagger$ & $0.012 \pm 0.010$ & $0.012 \pm 0.004 \uparrow$ \\
\hline Serum total cholesterol $(\mathrm{mmol} / \mathrm{l})$ & $0.048 \pm 0.011 \dagger$ & $0.113 \pm 0.019 \uparrow$ & $0.41 \pm 0.10 \uparrow$ & $-0.09 \pm 0.15$ & $0.005 \pm 0.003$ & $0.071 \pm 0.030^{*}$ & $-0.097 \pm 0.053 \ddagger$ & $0.027 \pm 0.023$ \\
\hline Smoking $(0=$ no, $I=$ yes $)$ & $-0.009 \pm 0.025$ & $0.244 \pm 0.043 \dagger$ & $1.05 \pm 0.22 \uparrow$ & $2.55 \pm 0.34 \uparrow$ & $0.057 \pm 0.008 \uparrow$ & $0.043 \pm 0.066$ & $-0.006 \pm 0.107$ & $0.006 \pm 0.049$ \\
\hline Alcohol intake $(0=$ no, $I=$ yes $)$ & $-0.017 \pm 0.032$ & $0.010 \pm 0.056$ & $0.20 \pm 0.29$ & $0.80 \pm 0.44 \ddagger$ & $0.012 \pm 0.010$ & $-0.071 \pm 0.087$ & $0.009 \pm 0.141$ & $-0.056 \pm 0.083$ \\
\hline Oral contraceptives $(0=\mathrm{no}, \mathrm{I}=$ yes $)$ & $-0.022 \pm 0.029$ & $0.018 \pm 0.051$ & $0.06 \pm 0.26$ & $0.61 \pm 0.40 \ddagger$ & $0.012 \pm 0.009$ & $0.002 \pm 0.079$ & $-0.040 \pm 0.123$ & $0.157 \pm 0.067^{*}$ \\
\hline
\end{tabular}


Table 2 Unadjusted phenotype-genotype associations

Values are arithmetic mean \pm S.E.M. or geometric mean ( $95 \%$ confidence interval).

\begin{tabular}{|c|c|c|c|c|c|}
\hline \multirow[b]{2}{*}{ Parameter } & \multicolumn{2}{|l|}{$\mathbb{C C}$} & \multicolumn{2}{|c|}{$\mathrm{CT}+\mathrm{TT}$} & \multirow[b]{2}{*}{$P$ value } \\
\hline & $n$ & Unadjusted mean & $n$ & Unadjusted mean & \\
\hline \multicolumn{6}{|l|}{ Men } \\
\hline $\mathrm{RBC}$ count $\left(10^{12} / \mathrm{I}\right)$ & 737 & $4.87 \pm 0.01$ & 180 & $4.93 \pm 0.03$ & 0.03 \\
\hline Haemoglobin (mmol/l) & 735 & $9.18 \pm 0.02$ & 178 & $9.27 \pm 0.04$ & 0.05 \\
\hline Haematocrit (\%) & 737 & $44.5 \pm 0.1$ & 180 & $45.0 \pm 0.2$ & 0.05 \\
\hline MCV (fl) & 737 & $91.5 \pm 0.2$ & 180 & $91.4 \pm 0.4$ & 0.76 \\
\hline MCH (fmol) & 735 & $1.889 \pm 0.004$ & 178 & $1.884 \pm 0.009$ & 0.56 \\
\hline $\mathrm{MCHC}(\mathrm{mmol} / \mathrm{l})$ & 735 & $20.66 \pm 0.03$ & 178 & $20.62 \pm 0.06$ & 0.60 \\
\hline RDW (\%) & 413 & $13.70 \pm 0.05$ & III & $13.61 \pm 0.08$ & 0.35 \\
\hline Serum ferritin $(\mu g / l)$ & 245 & $180(159-203)$ & 52 & $142(108-186)$ & 0.11 \\
\hline \multicolumn{6}{|l|}{ Women } \\
\hline $\mathrm{RBC}$ count $\left(10^{12} / \mathrm{I}\right)$ & 748 & $4.44 \pm 0.01$ & 205 & $4.44 \pm 0.02$ & 0.94 \\
\hline Haemoglobin (mmol/l) & 743 & $8.32 \pm 0.02$ & 204 & $8.31 \pm 0.04$ & 0.84 \\
\hline Haematocrit (\%) & 748 & $40.7 \pm 0.1$ & 205 & $40.9 \pm 0.2$ & 0.45 \\
\hline MCV (fl) & 748 & $91.8 \pm 0.2$ & 205 & $92.2 \pm 0.3$ & 0.33 \\
\hline MCH (fmol) & 743 & $1.878 \pm 0.004$ & 204 & $1.876 \pm 0.008$ & 0.75 \\
\hline MCHC (mmol/l) & 743 & $20.46 \pm 0.03$ & 204 & $20.34 \pm 0.06$ & 0.09 \\
\hline RDW (\%) & 404 & $13.66 \pm 0.05$ & 127 & $13.62 \pm 0.09$ & 0.67 \\
\hline Serum ferritin $(\mu \mathrm{g} / l)$ & 239 & $70(62-79)$ & 76 & $71(57-89)$ & 0.87 \\
\hline
\end{tabular}

Table 3 Adjusted phenotype-genotype associations

Values are arithmetic mean \pm S.E.M. or geometric mean ( $95 \%$ confidence interval), and were adjusted for age, body mass index, serum total cholesterol, smoking and alcohol intake, and in women also for the use of oral contraceptives.

\begin{tabular}{|c|c|c|c|c|c|}
\hline \multirow[b]{2}{*}{ Parameter } & \multicolumn{2}{|l|}{$\mathrm{CC}$} & \multicolumn{2}{|c|}{$\mathrm{CT}+\mathrm{IT}$} & \multirow[b]{2}{*}{$P$ value } \\
\hline & $n$ & Adjusted mean & $n$ & Adjusted mean & \\
\hline \multicolumn{6}{|l|}{ Men } \\
\hline $\mathrm{RBC}$ count $\left(10^{12} / \mathrm{I}\right)$ & 737 & $4.86 \pm 0.01$ & 180 & $4.93 \pm 0.03$ & 0.02 \\
\hline Haemoglobin $(\mathrm{mmol} / \mathrm{l})$ & 735 & $9.18 \pm 0.02$ & 178 & $9.30 \pm 0.04$ & 0.02 \\
\hline Haematocrit (\%) & 737 & $44.4 \pm 0.1$ & 180 & $45.0 \pm 0.2$ & 0.02 \\
\hline MCV (fl) & 737 & $91.4 \pm 0.2$ & 180 & $91.4 \pm 0.4$ & 0.98 \\
\hline MCH (fmol) & 735 & $1.892 \pm 0.004$ & 178 & $1.890 \pm 0.008$ & 0.88 \\
\hline MCHC (mmol/l) & 735 & $20.70 \pm 0.04$ & 178 & $20.68 \pm 0.07$ & 0.72 \\
\hline RDW (\%) & 413 & $13.72 \pm 0.05$ & III & $13.60 \pm 0.08$ & 0.19 \\
\hline Serum ferritin $(\mu \mathrm{g} / \mathrm{l})$ & 245 & $176(156-199)$ & 52 & 144 (II4-183) & 0.16 \\
\hline \multicolumn{6}{|l|}{ Women } \\
\hline $\operatorname{RBC}$ count $\left(10^{12} / I\right)$ & 748 & $4.44 \pm 0.01$ & 205 & $4.41 \pm 0.02$ & 0.39 \\
\hline Haemoglobin $(\mathrm{mmol} / \mathrm{l})$ & 743 & $8.32 \pm 0.02$ & 204 & $8.30 \pm 0.04$ & 0.54 \\
\hline Haematocrit (\%) & 748 & $40.7 \pm 0.1$ & 205 & $40.8 \pm 0.2$ & 0.70 \\
\hline MCV (fl) & 748 & $91.8 \pm 0.2$ & 205 & $92.2 \pm 0.3$ & 0.31 \\
\hline MCH (fmol) & 743 & $1.882 \pm 0.004$ & 204 & $1.879 \pm 0.008$ & 0.76 \\
\hline $\mathrm{MCHC}(\mathrm{mmol} / \mathrm{l})$ & 743 & $20.50 \pm 0.04$ & 204 & $20.37 \pm 0.06$ & 0.06 \\
\hline RDW (\%) & 404 & $13.64 \pm 0.06$ & 127 & $13.61 \pm 0.10$ & 0.84 \\
\hline Serum ferritin $(\mu \mathrm{g} / \mathrm{l})$ & 239 & $70(63-77)$ & 76 & $73(61-88)$ & 0.63 \\
\hline
\end{tabular}




\begin{tabular}{|c|c|c|c|c|c|c|}
\hline \multicolumn{2}{|l|}{ Phenotype } & \multicolumn{2}{|c|}{ Drinkers } & \multicolumn{2}{|c|}{ Non-drinkers } & \multirow{2}{*}{$P-i n$} \\
\hline & $n$ & & $P$ & $n$ & $P$ & \\
\hline RBC $\left(10^{12} / L\right)$ & 329 & 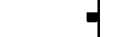 & 0.002 & 588 & 0.70 & 0.03 \\
\hline Haemoglobin (mr & $\mathrm{mol} / \mathrm{L}) 328$ & - & 0.004 & 585 & 0.95 & 0.03 \\
\hline Haematocrit (\%) & 329 & $\longrightarrow$ & 0.004 & 588 & 0.74 & 0.04 \\
\hline $\mathrm{MCV}(\mathrm{fL})$ & 329 & & 0.79 & 588 & 0.87 & 0.90 \\
\hline $\mathrm{MCH}$ (fmol/40) & 328 & & 0.67 & 585 & 0.70 & 0.91 \\
\hline $\mathrm{MCHC}(\mathrm{fmol} / \mathrm{L})$ & 328 & & 0.71 & 585 & 0.71 & 0.97 \\
\hline \multirow[t]{2}{*}{ RDW (\%) } & 177 & $\rightarrow$ & 0.26 & 347 & 0.05 & 0.04 \\
\hline & $\begin{array}{c}-3.0 \\
\text { cc lower }\end{array}$ & -1.5 & $\begin{array}{c}1.5 \\
\text { CC higher }\end{array}$ & $\begin{array}{c}-1.0 \\
\mathrm{CC} \text { lower }\end{array}$ & $\begin{array}{l}0.0 \quad 1.0 \\
\text { CC higher }\end{array}$ & \\
\hline
\end{tabular}

Figure I Unadjusted phenotype-genotype associations by alcohol intake in men

Closed (drinkers) and open (non-drinkers) symbols represent the mean differences between $\beta$-adducin $\mathrm{CC}$ homozygotes and $\mathrm{T}$ allele carriers ( $C \mathrm{C}$ minus $\mathrm{T}$ allele carriers). Horizontal lines denote $95 \%$ confidence intervals (Cl). Number of subjects $(n)$ and significance levels $(P)$ for the differences between $C($ homozygotes and $\mathrm{T}$ allele carriers and for interaction between $\beta$-adducin genotype and alcohol intake $\left(P_{\text {-int }}\right)$ are given. For abbreviations, see text.

\begin{tabular}{|c|c|c|c|c|c|c|}
\hline \multicolumn{2}{|l|}{ Phenotype } & \multicolumn{2}{|c|}{ Drinkers } & \multicolumn{2}{|c|}{ Non-drinkers } & \multirow{2}{*}{$P-i n t$} \\
\hline & $n$ & & $P$ & $n$ & $P$ & \\
\hline $\operatorname{RBC}\left(10^{12} / L\right)$ & 329 & & 0.02 & 588 & 0.46 & 0.06 \\
\hline Haemoglobin (mn & $\mathrm{nol} / \mathrm{L}) 328$ & $=$ & 0.005 & 585 & 0.21 & 0.05 \\
\hline Haematocrit (\%) & 329 & $\rightarrow$ & 0.02 & $588^{-}$ & 0.21 & 0.09 \\
\hline $\operatorname{MCV}(\mathrm{fl})$ & 329 & & -0.79 & $588^{-}$ & 0.87 & 0.92 \\
\hline $\mathrm{MCH}(\mathrm{fmo} / 10)$ & 328 & & 0.66 & 585 & 0.90 & 0.93 \\
\hline $\mathrm{MCHC}(\mathrm{fmol} / \mathrm{L})$ & 328 & & 0.65 & 585 & 0.87 & 0.94 \\
\hline RDW (\%) & 177 & & 0.32 & 347 & 0.05 & 0.05 \\
\hline & $\begin{array}{c}-3.0 \\
\text { CC lower }\end{array}$ & -1.5 & $\begin{array}{c}1.5 \\
\text { CC higher }\end{array}$ & $\begin{array}{c}-1.0 \\
\operatorname{cc} \text { lower }\end{array}$ & $\begin{array}{l}0.0 \quad 1.0 \\
\text { CC higher }\end{array}$ & \\
\hline
\end{tabular}

Figure 2 Adjusted phenotype-genotype associations by alcohol intake in men

Values were adjusted for age, body mass index, serum total cholesterol and smoking. For further explanations, see Figure I.

In GEE analyses adjusted for sex, age, body mass index and serum total cholesterol, the relative risk of biliary stones was 3.07 ( $95 \%$ confidence interval $0.71-13.4 ; P=$ 0.13 ) in CC homozygotes compared with $\mathrm{T}$ allele carriers.

\section{DISCUSSION}

Our present study demonstrates that CC homozygosity with regard to the $\beta$-adducin C1797T polymorphism was associated with decreased values of RBC count, haemoglobin concentration and haematocrit in men who consumed alcohol, but not in non-drinking men or in all women.
Our present findings are in accordance with the results of two previously published studies in $\beta$-adducin-deficient knock-out mice [3,4]. In the absence of $\beta$-adducin, the amount of $\alpha$-adducin in the membrane skeleton of mouse RBCs decreased by amounts ranging from $30 \%$ [3] to $80 \%$ [4], whereas the incorporation of $\gamma$-adducin rose 4-fold [4] to 5-fold [3]. Moreover, $\beta$-adducindeficient knock-out mice had significantly decreased haematocrit, haemoglobin level and $\mathrm{MCH}$, but increased MCHC. RBCs from $\beta$-adducin-deficient mice were smaller and showed a variable morphology, including normal RBCs, elliptocytes, rounded elliptocytes, stomatocytes and spherocytes [3,4]. $\beta$-Adducin-null RBCs also showed increased osmotic fragility and decreased concentrations of intracellular cations $[3,4]$. Moreover, the reticulocyte count in peripheral blood $[3,4]$ and the serum concentration of bilirubin were higher in $\beta$-adducin-deficient mice than in control animals [4].

We did not perform any morphological measurements on RBCs. However, the analogy between the observations in $\beta$-adducin-deficient mice [3,4] and our present findings in men who drink alcohol suggests that the $\beta$-adducin C1797T polymorphism or other $\beta$-adducin mutations in linkage disequilibrium with the C1797T polymorphism might impact on the assembly of the membrane skeleton of RBCs, and hence on their maturation, or their release into or removal from the circulation.

We did not have any direct evidence of haemolysis, such as an elevated reticulocyte count, a higher serum concentration of bilirubin, poikilocytosis or increased osmotic fragility of the RBCs [11]. However, in men and women alike, the serum ferritin level, as an index of body iron stores [12], did not differ between the $\beta$-adducin genotypes. Thus iron deficiency is unlikely to explain our present observations [13]. On the other hand, the higher risk of biliary stones in CC homozygotes may be viewed as an indirect indication of chronic haemolysis [11]. Furthermore, the interaction in men between the $\beta$ adducin genotype and alcohol intake also supports the concept of increased haemolysis in CC homozygotes. Indeed, it is well known that alcoholism is associated with a variety of haematological disorders [14,15]. Longterm ingestion of large quantities of alcohol may decrease the formation of haematopoietic cells, increase their destruction and alter their morphology and function, leading to anaemia $[14,15]$. In the $\beta$-adducin CC homozygotes who consumed alcohol, ethanol may decrease the production of RBCs and/or cause faster elimination of the more fragile RBCs. In contrast, in nondrinking men, RBCs may remain in the circulation for longer, with a compensatory upsurge in reticulocytes, resulting in a higher RDW due to the presence of heterogeneous RBCs and an increased variation in their volume. 
Several factors might explain the null findings in women. First, compared with men, fewer women drank alcohol $(35.9 \%$ of men and $13.3 \%$ of women; $P<$ 0.0001). Secondly, haematological phenotypes such as the RBC count, haemoglobin level and haematocrit are influenced by menstrual blood loss and by the use of oral contraceptives or hormone replacement therapy [16]. Furthermore, fluctuation in the female sex hormones due to the menstrual cycle or menopause may also mask haematological phenotypes associated with genetic mutation of the $\beta$-adducin gene [16].

The function of the $\beta$-adducin C1797T polymorphism is still unknown. Lower values of RBC count, haemoglobin concentration and haematocrit were observed in men who were homozygous for the major allele (C) and who drank alcohol. During a person's lifetime, increased fragility of RBCs in relation to the C1797T variation in the $\beta$-adducin gene might facilitate the pathogenesis of disorders such as, for instance, cholelithiasis or acute or chronic cholecystitis or cholangitis [17]. However, CC homozygotes may also experience some health benefits. Indeed, it has been shown that frequent and long-term whole-blood donation is associated with a low risk of cardiovascular disease [18]. Moreover, we showed previously that CC homozygous women had a lower risk of hypertension [19].

In conclusion, in men consuming alcohol, the $\beta$ adducin CC genotype with regard to the C1797T polymorphism is associated with lower values of $\mathrm{RBC}$ count, haemoglobin concentration and haematocrit. We hypothesize that, in CC homozygous men, alcohol consumption may unveil the greater fragility of RBCs, and that the CC genotype may slightly potentiate the structural and functional haematological disturbances that are induced gradually by increasing alcohol intake. Our working hypothesis is in line with the proven role of adducin in maintaining the integrity of the membrane skeleton of RBCs, as well as with the haematological abnormalities observed in $\beta$-adducin knock-out mice. However, further molecular studies are required to elucidate the influence of the C1797T polymorphism on the transcription and translation of $\beta$-adducin and on the stability of the RBC membrane.

\section{ACKNOWLEDGMENTS}

The FLEMENGHO Study was supported by a research grant G.0424.03 from the Fonds voor Wetenschappelijk Onderzoek Vlaanderen (Brussels, Belgium), the Bilaterale Wetenschappelijke en Technische Samenwerking Vlaanderen-China (project BIL98/15) and a special research grant from the Katholieke Universiteit Leuven (Onderzoekstoelage OT99/28). Families were recruited in the framework of the European Project on Genes in Hypertension, which was partially financed by the
European Union (contract number IC15-CT98-0329EPOGH). The epidemiological work in Belgium and the genetic research in Milan, Italy, were conducted in the framework of the EURNETGEN project (EU grant number QLG1-CT-2000-01137). The genetic laboratory also received grants from the Ministero della Sanità (Italy) to G.B. (RF200-00-49) and the Ministero Università e Ricerca Scientifica (Italy) to C.B. (ex MPI 60\% 2000). The FLEMENGHO study would not have been possible without the collaboration of the family physicians of the participants. The municipality HechtelEksel (Belgium) provided logistical support. We acknowledge the expert assistance of Leszek Bieniaszewski, Rina Bollen, Lut De Pauw, Hilde Celis, Elly Den Hond, Primoz Dolenc, Paul Drent, Dmitri Emelianov, Jerzy Gąsowski, Heng Fan, Lieve Gijsbers, Alida Hermans, Tatyana Kuznetsova, Muzi Maseko, Tim Nawrot, Agnieszka Olszanecka, Katarzyna Stolarz, Lutgarde Thijs, Valérie Tikonoff, Yvette Toremans, Sylvia Van Hulle and Renilde Wolfs (Study Coordinating Centre, Leuven, Belgium).

\section{REFERENCES}

1 Matsuoka, Y., Li, X. and Bennett, V. (2000) Adducin: structure, function and regulation. Cell. Mol. Life Sci. 57, 884-895

2 Matsuoka, Y., Hughes, C. A. and Bennett, V. (1996) Adducin regulation. Definition of calmodulin-binding domain and sites of phosphorylation by protein kinases A and C. J. Biol. Chem. 271, 25157-25166

3 Gilligan, D. M., Lozovatsky, L., Gwynn, B., Brugnara, C., Mohandas, N. and Peters, L. L. (1999) Targeted disruption of the $\beta$ adducin gene (Add2) causes red blood cell spherocytosis in mice. Proc. Natl. Acad. Sci. U.S.A. 96, 10717-10722

4 Muro, A. F., Marro, M. L., Gajovic, S., Porro, F., Luzzatto, L. and Baralle, F. E. (2000) Mild spherocytic hereditary elliptocytosis and altered levels of $\alpha$ - and $\gamma$-adducins in $\beta$-adducin-deficient mice. Blood 95, 3978-3985

5 Gilligan, D. M., Lozovatsky, L. and Silberfein, A. (1997) Organization of the human $\beta$-adducin gene (ADD2). Genomics 43, 141-148

6 Staessen, J. A., Roels, H. A., Emelianov, D. et al. (1999) Environmental exposure to cadmium, forearm bonedensity, and risk of fractures: prospective population study. Lancet 353, 1140-1144

7 Bernard, A. M. and Lauwerys, R. R. (1983) Continuousflow system for automation of latex immunoassay by particle counting. Clin. Chem. 29, 1007-1011

8 Staessen, J. A., Fagard, R. and Amery, A. (1994) Life style as a determinant of blood pressure in the general population. Am. J. Hypertens. 7, 685-694

9 Livak, K. J., Flood, S. J., Marmaro, J., Giusti, W. and Deetz, K. (1995) Oligonucleotides with fluorescent dyes at opposite ends provide a quenched probe system useful for detecting PCR product and nucleic acid hybridization. PCR Methods Appl. 4, 357-362

10 Zeger, S. L., Liang, K. Y. and Albert, P. S. (1988) Models for longitudinal data: a generalized estimating equation approach. Biometrics 44, 1049-1060

11 Bolton-Maggs, P. H. (2000) The diagnosis and management of hereditary spherocytosis. Baillière's Clin. Haematol. 13, 327-342 
12 Guyatt, G. H., Oxman, A. D., Ali, M., Willan, A., Mcllroy, W. and Patterson, C. (1992) Laboratory diagnosis of iron-deficiency anemia: an overview. J. Gen. Intern. Med. 7, 145-153

13 Fleming, D. J., Jacques, P. F., Tucker, K. L. et al. (2001)

Iron status of free-living, elderly Framingham Heart Study cohort: an iron-replete population with a high prevalence of elevated iron stores. Am. J. Clin. Nutr. 73, 638-646

14 Ballard, H. S. (1989) Hematological complications of alcoholism. Alcoholism 13, 706-720

15 Colman, N. and Herbert, V. (1980) Hematologic complications of alcoholism: overview. Semin. Hematol. $17,164-176$
16 Milman, N., Clausen, J. and Byg, K. E. (1998) Iron status in 268 Danish women aged 18-30 years: influence of menstruation, contraceptive method, and iron supplementation. Ann. Hematol. 77, 13-19

17 Kalloo, A. N. and Kantsevoy, S. V. (2001) Gallstones and biliary disease. Prim. Care 28, 591-606

18 Meyers, D. G., Jensen, K. C. and Menitove, J. E. (2002) A historical cohort study of the effect of lowering body iron through blood donation on incident cardiac events. Transfusion 42, 1135-1139

19 Wang, J. G., Staessen, J. A., Barlassina, C. et al. (2002) Association between hypertension and variation in the $\alpha$ - and $\beta$-adducin genes in a white population. Kidney Int. 62, 2152-2159

Received 3 July 2002/25 November 2002; accepted 7 January 2003 